\title{
OPTIMIZATION OF SOLAR ENERGY FOR SALT EXTRACTION FROM LAKE KATWE, UGANDA
}

\author{
KASEDDE H. ${ }^{1,2, *}$ \\ LWANYAGA J.D. ${ }^{2}$ \\ KIRABIRA J.B. ${ }^{2}$ \\ BÄBLER M.U. ${ }^{3}$
}

\author{
${ }^{1}$ Department of Materials Science and Engineering \\ KTH Royal Institute of Technology, Brinellvägen 23 \\ SE-100 44 Stockholm, Sweden \\ ${ }^{2}$ Department of Mechanical Engineering \\ College of Engineering, Design, Art and Technology \\ Makerere University, P.O. Box 7062, Kampala, Uganda \\ ${ }^{3}$ Department of Chemical Engineering and Technology \\ KTH Royal Institute of Technology, Teknikringen 42 \\ SE-100 44 Stockholm, Sweden
}

Received: $12 / 02 / 2014$

Accepted: 26/05/2015

Available online: $27 / 05 / 2015$ *to whom all correspondence should be addressed: e-mail: hillary@kth.se

\section{ABSTRACT}

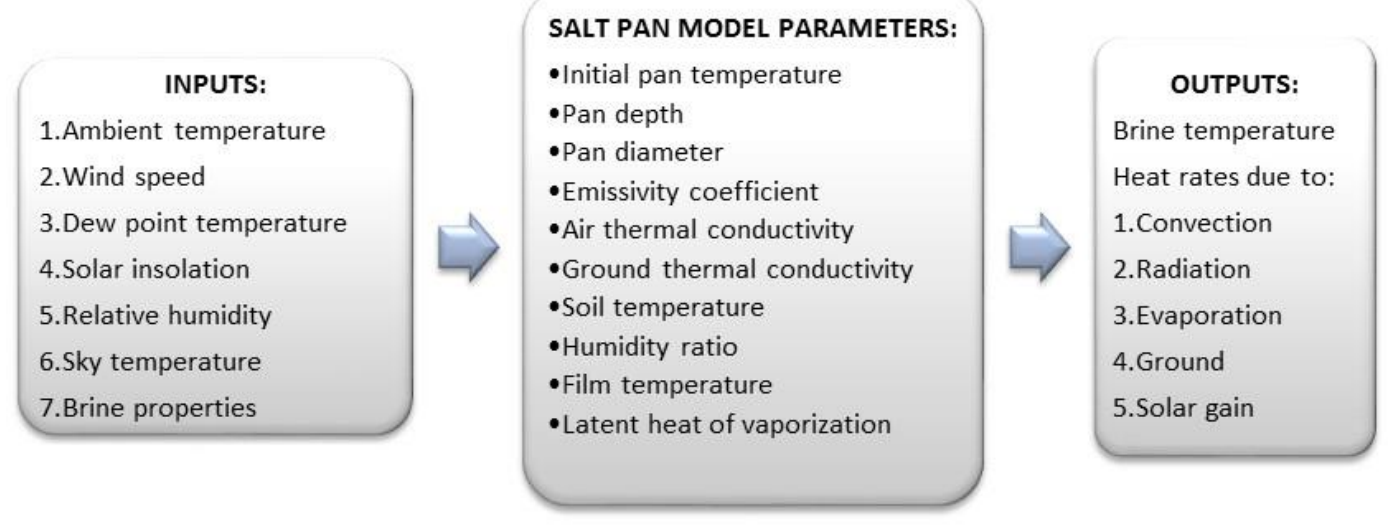

The solar evaporative crystallization process at Lake Katwe was studied using brine evaporation rates, thermal, convection, and radiation energy losses as well as reported meteorological data around the salt lake basin. A simulation model of a salt pan was developed on a lumped basis to study its behaviour with the effects of the different factors affecting the evaporation process investigated. Moreover, an analysis to assess the possibility of increased productivity of the salt pans through implementation of parabolic solar collector technology to enhance brine evaporation was done. Results showed that the brine evaporation rates and temperature of the salt pan are strongly influenced by in-situ weather conditions. Furthermore, a thermal-fluid analysis of the proposed system showed that the pond solution layer temperature increases thereby increasing the evaporation flux hence leading to increased salt production rate.

Keywords: solar evaporation, crystallization, salt pan, simulation, Lake Katwe 


\section{Introduction}

Lake Katwe is a closed hypersaline lake located within the Katwe-Kikorongo cluster of phreatomagnetic explosion craters in the western arm of the East African rift system in south-western Uganda. At an elevation of $885 \mathrm{~m}$, the lake occupies a maximum area of $2.5 \mathrm{~km}^{2}$, circumference of $9 \mathrm{~km}$, and a depth ranging from 0.4 to $1.6 \mathrm{~m}$. The lake comprises a circular western portion about $1.5 \mathrm{~km}$ in diameter from which an arm branches off to the northeast. It has been preliminary estimated that there is a total of 22.5 million tonnes of crystalline salts present in Lake Katwe (UDC, 1997). The lake natural brine is hydrochemically of a carbonate type, forming a mineral assemblage characterized by alkaline minerals rich in $\mathrm{Na}^{+}$, $\mathrm{K}^{+}, \mathrm{Cl}^{-}, \mathrm{SO}_{4}{ }^{2-}, \mathrm{CO}_{3}{ }^{2-}$, and $\mathrm{HCO}_{3}{ }^{-}$. The brine represents an important source of mineral salts suitable for domestic and industrial uses. The salts are composed of mainly halite mixed with other impurities such as carbonates, bicarbonates, and sulfates of sodium and potassium respectively. Thermodynamic calculations based on Pitzer's ion interaction model indicate that the lake brine is under-saturated with respect to the major dissolved mineral salts (Kasedde et al., 2014).

Presently, the salts are recoverable by traditional solar evaporation techniques from over 10,000 salt pans located around the periphery of the lake which vary in surface area from less than $24 \mathrm{~m}^{2}$ to around $400 \mathrm{~m}^{2}$, and in depth from 0.3 to $1 \mathrm{~m}$. Quality is highly variable and uncontrollable and as such, the crystallized salts are generally impure and of small yields. The salts are classified into three grades (I, II, and III) based on the visible impurities. They are mainly used as animal feed supplements, fertilizers, and for industrial uses such as leather tanning and textile production. Salt is extracted only during hot, dry seasons, from February to April, and July to September every year when a considerable amount of energy is required to heat up the brine in the salt pans. Figure 1 shows the flow chart of the traditional salt extraction process at Lake Katwe. Although there is no comprehensive record keeping at the site, current production is reported at 15,000 tonnes with the value only increasing slightly over the past 50 years (Kirabira et al., 2013). It should also be noted that there is direct mining of salt crusts from the lake bed using iron bar levers.

Solar energy is an important energy resource for salt precipitation from Lake Katwe brine. This is due to its remote location and the local climate conditions with isolation levels of up to $965 \mathrm{~W} \mathrm{~m}^{-2}$, annual evaporation and precipitation levels of 2,160 and $900 \mathrm{~mm}$ respectively (Kirabira et al., 2013). Moreover, solar energy is one source of free energy that is inexhaustible in supply and use. Many processes in the mining and mineral processing industry, such as fractional crystallization and leaching lend themselves to solar applications. These operations constitute a major portion of the chemical processing employed in the purification and concentration of salts from brine. Enhancing brine evaporation in the solar ponds can be used not only as a means to offset energy costs to improve efficiency, but also to provide a suitable processing environment (Lesino et al., 1991; Folchitto 1991; Guijt et al., 1999).

A number of experimental and modeling investigations directed towards the utilization of solar energy to enhance brine evaporation have been reported in literature. Abdel-Aal and Al-Naafa, 1993 investigated the enhanced evaporation of saline water in multi-purpose solar desalination units using flat-plat solar collectors. Their results showed that the concentrated solar energy input was estimated to be 3.5 times than that of direct solar flux allowing separation of soluble mineral salts such as $\mathrm{NaCl}, \mathrm{MgCl}_{2}$ and others. Zhang et al., 1993 presented a simulation model of evaporating brine by solar radiation for salt production where the different parameters involved in the behavior of the salt pan were studied. Huang et al., 1999 investigated the effect of a black insulation sheet on the evaporation rate from a shallow salt pan. Results showed that the evaporation rate of the salt pan increased by $10 \%$. In another attempt, Collares-Pereira et al., 2007 demonstrated an advanced solar dryer to optimize the recovery of salts from brine effluent of a desalination plant. Tamimi and Rawajfeh, 2007 modeled the thermal performance of solar evaporative ponds charged from Dead Sea water. The model results showed that the efficiency of any solar evaporator is limited by the optical absorptivity of the saline water as an upper limit. Zeng et al., 2011 demonstrated a 
strategy for solar evaporation enhancement using floating light-absorbing magnetic particles. In their investigation, evaporation was enhanced by a factor of 2.3 in the solar evaporation of $3.5 \%$ water. Diaz et al., 2012 described an analysis to assess the increased productivity of sea salt from Southern Spain by using concentrated solar thermal energy systems. Their results showed that the enhanced system could evaporate water six to ten times faster than the natural evaporation process. More recently, Horri et al., 2014 modeled the solar evaporation process assisted by floating light porous materials. The model results showed that the evaporation rate can be enhanced by approximate factors of $2.3,2$, and 1.8 when using $0.045,0.023$, and $0.015 \mathrm{~g}$ of light absorbing material respectively.

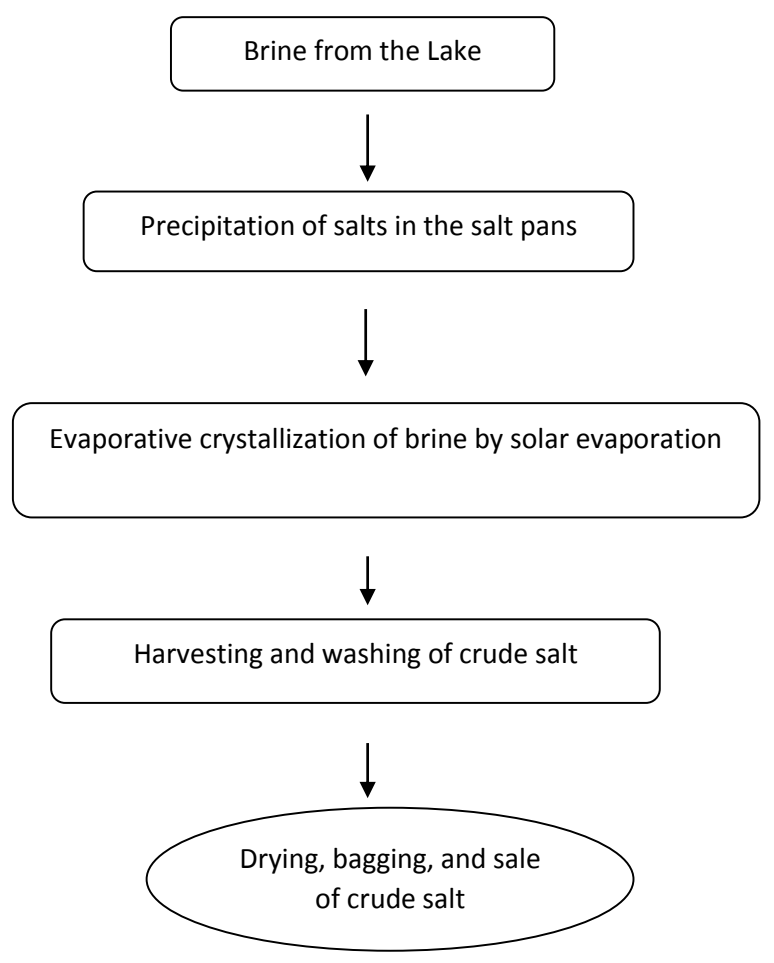

Figure 1. Current (traditional) salt processing methods at Lake Katwe.

Although the solar evaporation technique has been used to extract salt at Lake Katwe for several decades, little efforts have been made to date to assess the possibility to intensify the brine evaporation process in the shallow pans to produce salt. As a result, the production continues to depend mainly on the daily ambient temperature and prevailing winds to promote evaporation hence very low productivities. Thus, the main objective of this work is to: (a) study the evaporation rate of brine under natural field conditions at Lake Katwe in relation to various parameters, (b) to propose and analyze a method designed to provide a brine evaporation rate enhancement over the present conventional method hence leading to the improvement in the current traditional salt extraction industry.

\section{Experimental and modeling methods}

\subsection{Experimental methods}

A standard class A circular evaporation pan (model 255-200 Novalynx, USA), 1,024 mm in diameter and 254 $\mathrm{mm}$ deep was used to measure evaporation rates. The pan was installed on level ground at the end of the 
cause-way into the salt lake to simulate the evaporation conditions as close as possible. It was inspected for leaks before the start of the experiment followed by filling it with natural brine to within 2.5 inches of the top. The brine drop in the pan due to evaporation was monitored by a meter stick. Type $\mathrm{K}$ thermocouples (TJ1-CAXL-IM45U-1000/5000) and a smart Reader Plus 6 data logger (SRP-6-1.5M) were used for brine temperature measurements with an accuracy of $\pm 0.5 \%$ and resolution of $0.3^{\circ} \mathrm{C}$. The daily brine levels in the pan were monitored every after three hours starting at 0900 hours up to 1800 hours for seven consecutive days during the dry season in March 2012. Daily evaporation rates were computed using the level readings in the pan and daily rainfall figures reported from a Davis Vantage Pro 2 weather station. Moreover, the weather station was used to measure and record in-situ wind speeds, ambient temperature, rainfall, solar radiation, and relative humidity every 30 minutes during the experimental period.The weather station was installed on the rooftop of a building near the cause-way into the salt lake, 5 meters from the ground level. The data was processed using WeatherLink software. The accuracy of the integrated sensor suite (ISS) of the weather station for measuring each climatic variable was $0.5^{\circ} \mathrm{C}$ for ambient temperature, $\pm 5 \%$ for wind speed, $\pm 5 \%$ for rainfall, $\pm 4 \%$ for solar radiation, and $\pm 3 \%$ for relative humidity.

At the same time, a $50 \mathrm{ml}$ brine sample was taken from the evaporation pan at the end of each day for the determination of the physico-chemical parameters such as; the electrical conductivity, salinity, and $\mathrm{NaCl} \%$ which were measured using an electrode probe meter (HANNA instruments HI 98360, Woonsocket, RI, USA) with an accuracy of $\pm 0.5 \%$. Brine density was measured by a portable densito-meter (DMA 35 Anton Paar, Graz Österreich, Austria) with an accuracy of $\pm 0.001 \mathrm{~g} \mathrm{~cm}^{-3}$.

\subsection{Model development}

The cross section of the evaporation pan system studied is shown in Figure 2. The depth of the brine layer was very thin and therefore, it was appropriate to apply the lumped heat capacity analysis as the governing equation of the system. For the system equilibrium, it is also assumed that temperature and salinity are uniform. The thermal energy balance equation (1) represented by a time and temperature dependence equation is used with the heat gains or losses due to ground water seepage not being considered. The mathematical model is developed according to Chiasson et al., 2000.

$$
\mathrm{q}_{\text {in }}-\mathrm{q}_{\text {out }}=\mathrm{vpc}_{\mathrm{p}} \frac{\mathrm{dT}}{\mathrm{dt}}
$$

The heat transfer mechanisms considered are expressed in equation (2). Heat loss due to ground water seepage was negligible compared to the other losses in the analysis.

$$
\frac{\mathrm{dT}}{\mathrm{dt}}=\frac{\left(\mathrm{q}_{\text {solar }}+\mathrm{q}_{\text {thermal }}+\mathrm{q}_{\text {convection }}+\mathrm{q}_{\text {ground }}+\mathrm{q}_{\text {ground water }}+\mathrm{q}_{\text {evaporation }}\right)}{\mathrm{v} \rho \mathrm{c}_{\mathrm{p}}}
$$

The solar radiant heat gain is the major contributor of energy to the system. Parameters considered include the insolation and brine reflectance taken as $10 \%$ (Tamimi and Rawajfeh, 2007). Considering a circular pan area as the physical model studied in this work, the solar radiant heat gain is computed:

$$
\mathrm{q}_{\text {solar }}=(1-\mathrm{p}) \mathrm{A}_{\mathrm{pan}}
$$

The heat transfer at the pan surface due to the long wave or thermal radiation is modeled as shown by equation (4)

$$
\mathrm{q}_{\text {thermal }}=\mathrm{h}_{\mathrm{r}} \mathrm{A}_{\mathrm{pan}}\left(\mathrm{T}_{\mathrm{sky}}-\mathrm{T}_{\mathrm{pan}}\right)
$$

Where $h_{r}$ is calculated as: 
$h_{r}=4 \varepsilon \sigma\left(\frac{T_{p a n}+T_{\text {sky }}}{2}\right)^{3}$

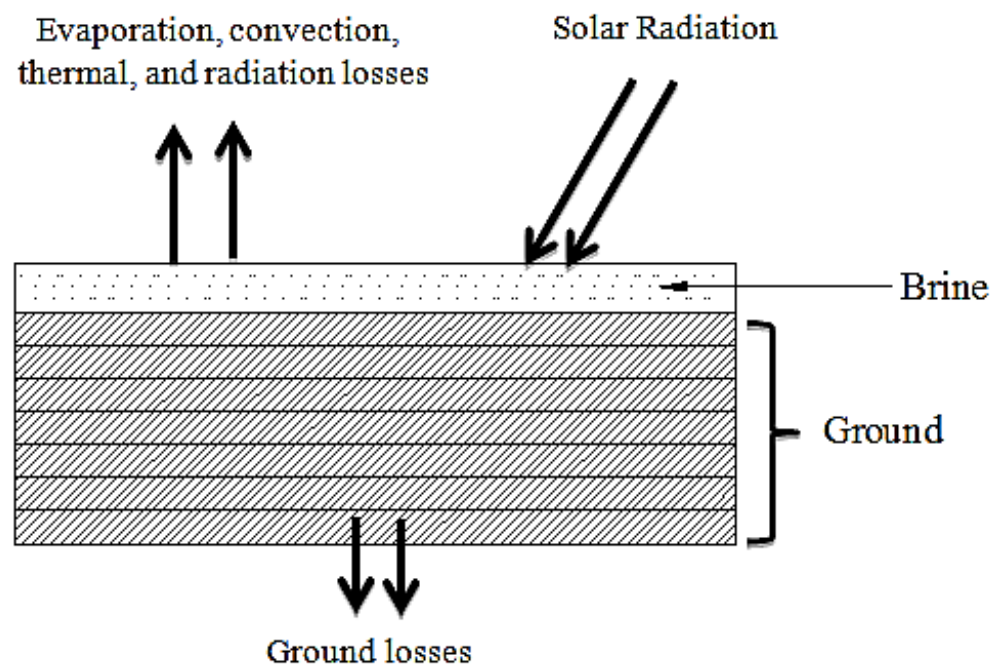

Figure 2. Cross section view of the physical model of the evaporation pan system

A similar approach is used to estimate the convective heat transfer between the soil and the brine in the pan since the impact of the heat transfer from the soil to the brine is relatively small compared to others. Equation (6) models the convective heat transfer at the pan surface.

$\mathrm{T}_{\text {sky }}=0.055 \mathrm{~T}_{\mathrm{a}}^{1.5}$

$\mathrm{q}_{\text {convection }}=\mathrm{h}_{\mathrm{c}} \mathrm{A}_{\mathrm{pan}}\left(\mathrm{T}_{\mathrm{air}}-\mathrm{T}_{\text {pan }}\right)$

Where $h_{c}$ is calculated as:

$\mathrm{h}_{\mathrm{c}}=\frac{\mathrm{Nuk}}{\mathrm{L}}$

For wind velocities, the convective heat loss coefficient is based on (Duffie and Beckman, 2006)

$\mathrm{h}_{\mathrm{c}}=2.8+3.0 \mathrm{U}_{0}$

Considering free convection, when there is no wind, two empirical relations for the Nusselt number are used in the model:

$\mathrm{h}_{\mathrm{c}}=2.8+3.0 \mathrm{U}_{0}$

$\mathrm{Nu}=0.54 \mathrm{Ra}^{\frac{1}{4}}$

$\left(10^{4}<\operatorname{Ra}<10^{7}\right)$

Laminar flow (10a)

$\mathrm{Nu}=0.15 \mathrm{Ra}^{\frac{1}{3}}$

$\left(10^{7}<\mathrm{Ra}<10^{10}\right)$

Turbulent flow (10b) 
The heat transfer due to evaporation is determined after estimating the various parameters in the evaporation heat transfer equation:

$$
\mathrm{q}_{\text {evaporation }}=\mathrm{H}_{\mathrm{fg}} \mathrm{A}_{\text {pond }} \mathrm{m}_{\mathrm{w}}
$$

where $m_{w}$ is the water mass transfer due to evaporation which is calculated as:

$$
\mathrm{m}_{\mathrm{w}}=\mathrm{h}_{\mathrm{d}}\left(\mathrm{w}_{\text {air }}-\mathrm{w}_{\text {surf }}\right)
$$

$h_{d}$ is the mass transfer coefficient and calculated as:

$$
h_{d}=\frac{h_{c}}{c_{p} L_{e}^{2 / 3}}
$$

$\mathrm{L}_{\mathrm{e}}$ is the Lewis number determined by equation determined by:

$$
\mathrm{L}_{\mathrm{e}}=\frac{\alpha}{\mathrm{D}_{\mathrm{AB}}}
$$

The heat gain from the ground by conduction is determined as:

$$
\mathrm{q}_{\text {ground }}=\mathrm{H}_{\mathrm{cg}} \mathrm{A}_{\text {pond }}\left(\mathrm{T}_{\text {soil }}-\mathrm{T}_{\mathrm{b}}\right)
$$

The mass of the theoretical crystallized salt is given by the following expression (Akridge, 2008):

$$
\mathrm{m}_{\mathrm{s}}=\mathrm{m}_{\mathrm{w}}\left(1.52 \times 10^{-4} \mathrm{~s}^{2}+9.50 \times 10^{-3} \mathrm{~S}\right)
$$

\subsection{Computational methodology}

The model equations were coded into Engineering Equation Solver (EES) simulation program (Alvarado and Klein, 2012) and solved iteratively. The measured meteorological data including the ambient temperature, wind speed, dew point temperature, solar radiation flux, and relative humidity was used as input to the model. To solve the overall energy balance equation, a differential equation was integrated using the initial brine temperature measured at $303 \mathrm{~K}$. The heat transfer equations required the mean brine temperature at each particular run in order to compute the respective heat transfer quantities. The brine temperature was determined iteratively with a convergence criterion of $8.9 \times 10^{-3} \mathrm{~K}$.

\section{Results and discussion}

\subsection{Evaporation rates}

To investigate the evaporation rates, physico-chemical parameters of the brine samples collected at the end of four experimental days were measured and reported in Table 1. Furthermore, average daily measured meteorological data is reported in Table 2.

Results from Table 1 above indicate the brine electrical conductivity, salinity, $\mathrm{NaCl}$ (\%), and density ranged between 127 to $127.4 \mathrm{mS} \mathrm{cm}^{-1}, 63.4$ to $63.7 \mathrm{~g} \mathrm{l}^{-1}, 24.84$ to $24.95 \%$ and 1.213 to $1.234 \mathrm{~g} \mathrm{~cm}^{-3}$ respectively. These results indicate that the brine in the pan concentrated with time. It is evident that under given meteorological conditions, the evaporation rate of brine falls with increasing salinity due to the lowered vapour pressure as a result of higher brine temperature. Furthermore, the molecular activity of the water is reduced as its salinity increases because molecules of dissolved solids interfere with the motion of water molecules. Evaporation rates also decline as density of the brine increases. Moreover, the average number 
of water molecules in contact with the air becomes smaller as salinity increases because part of the surface area is occupied by salt molecules. It has also been demonstrated that the rate of evaporation decreases with an increase in salt content until the salt content reaches about 30 percent, at which point a thin salt crust tends to form on the brine surface unless the solution is agitated (Turk, 1970).

Table 1. Physico-chemical parameters of the brine samples

\begin{tabular}{ccccc}
\hline Sample & Electrical Conductivity $\left(\mathrm{ms} \mathrm{cm}^{-1}\right)$ & Salinity $\left(\mathrm{g} \mathrm{l}^{-1}\right)$ & $\mathrm{NaCl}(\%)$ & Density $\left(\mathrm{g} \mathrm{cm}^{-3}\right)$ \\
\hline 1 & 127.0 & 63.4 & 24.84 & 1.220 \\
\hline 2 & 127.1 & 63.5 & 24.88 & 1.213 \\
\hline 3 & 127.0 & 63.6 & 24.86 & 1.234 \\
\hline 4 & 127.4 & 63.7 & 24.95 & 1.227 \\
\hline
\end{tabular}

Table 2. Meteorological data used for the calculation of the evaporation rates

\begin{tabular}{cccccc}
\hline Day & Wind speed $\left(\mathrm{m} \mathrm{s}^{-1}\right)$ & $\begin{array}{c}\text { Solar } \\
\text { Irradiation } \\
\left(\mathrm{Wh} / \mathrm{m}^{2} / \text { day }\right)\end{array}$ & $\begin{array}{c}\text { Solar } \\
\text { Evaporation } \\
(\mathrm{mm} / \text { day })\end{array}$ & $\begin{array}{c}\text { Ambient } \\
\text { Temperature } \\
\left({ }^{\circ} \mathrm{C}\right)\end{array}$ & $\begin{array}{c}\text { Relative Humidity } \\
(\%)\end{array}$ \\
\hline 1 & 1.47 & 2,115 & 4.8 & 31.15 & 45.0 \\
\hline 2 & 2.05 & 4,617 & 5.8 & 28.60 & 55.0 \\
\hline 3 & 1.47 & 4,512 & 3.9 & 28.95 & 52.0 \\
\hline 4 & 1.58 & 7,063 & 1.9 & 28.65 & 49.5 \\
\hline 5 & 2.25 & 3,394 & 1.9 & 29.75 & 47.5 \\
\hline 6 & 0.73 & 4,635 & 2.9 & 29.25 & 51.5 \\
\hline 7 & 1.34 & 1,840 & 1.9 & 26.80 & 57.0 \\
\hline
\end{tabular}

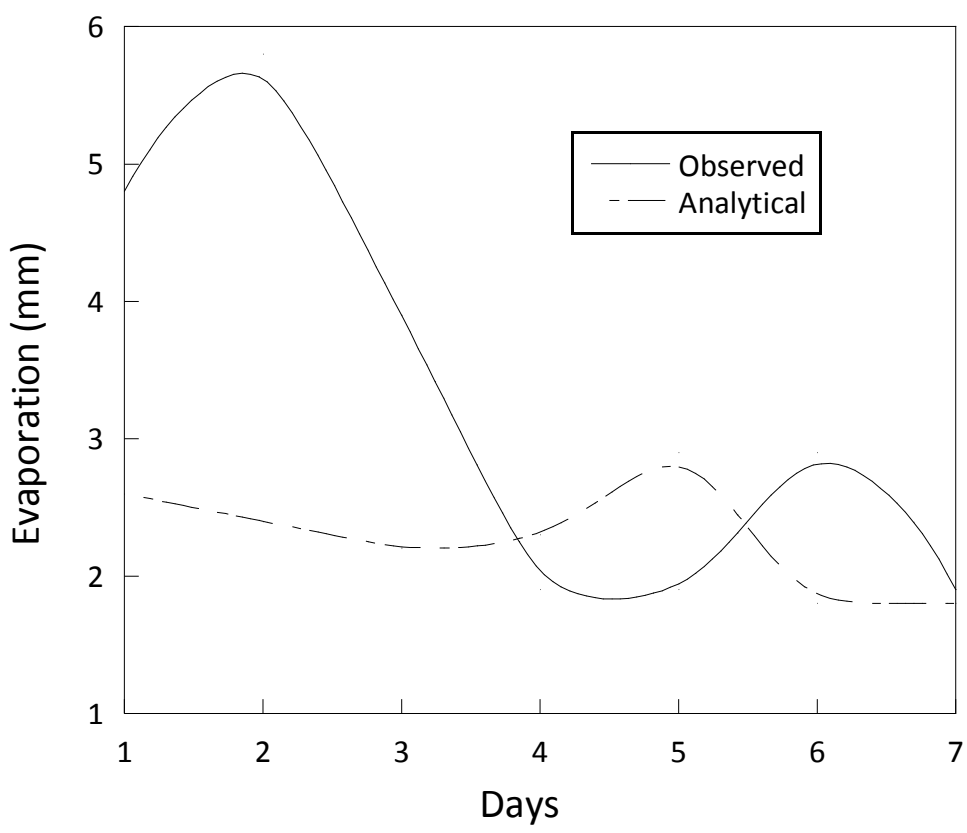

Figure 3. Comparative evaporation rates

The brine physico-chemical parameters were used to determine the analytical evaporation rates which were compared with the experimental evaporation rates (Figure 3). Results indicate that the observed and analytical evaporation rates are within the same range with the exception of the first four days. It is observed that the values differed slightly in the first four days which can be attributed to uncertainty in the 
determination of the brine physico-chemical properties, uncertainty in the measurement of the meteorological data such as rainfall and wind speeds. Other causes of the discrepancies could be due to the characteristics of the evaporation pan used such as the pan coefficient and the influence of local conditions at the evaporation pan site.

The theoretical salt crystallized during the evaporation period was estimated and compared with the amount of brine evaporated as shown in Figure 4. It can be deduced that as more water is evaporated, more salts crystallize. With time, as salinity increases, less water is evaporated and thus, less salt is crystallized. The model predicts that less salt is crystallized compared to the water evaporated although giving a similar trend.

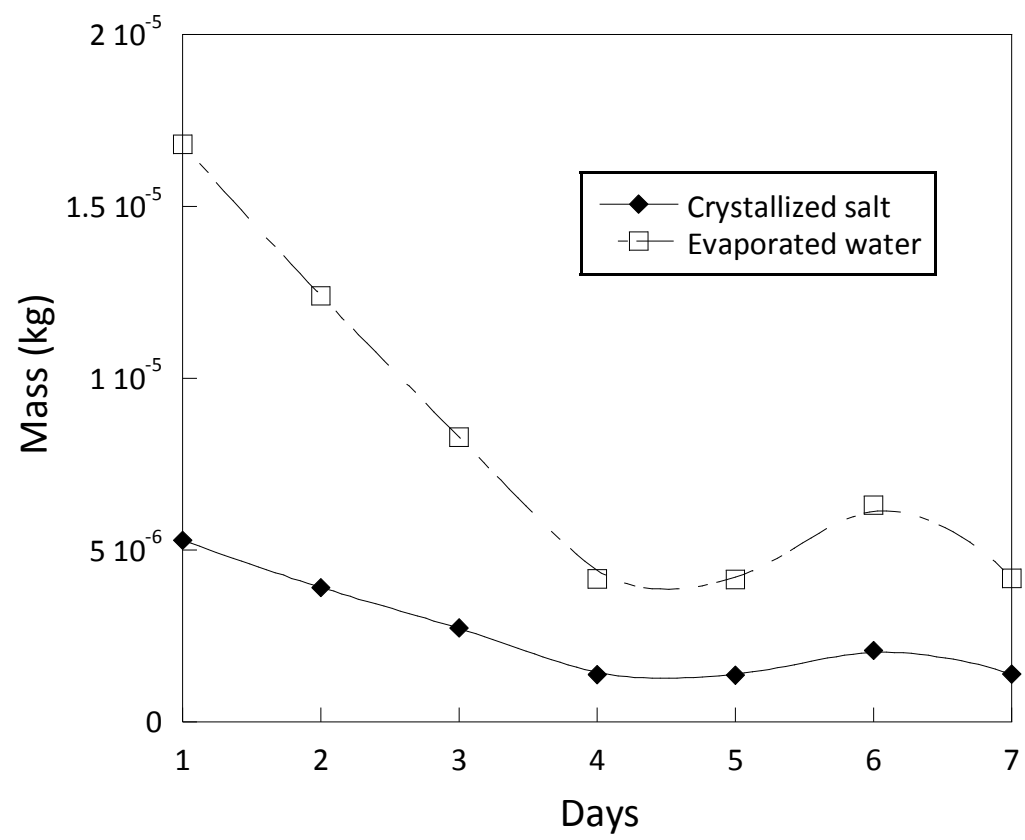

Figure 4. Brine evaporated and theoretical crystallized salt

\subsection{Model results}

\subsubsection{Predicted brine temperature variation}

Figure 5 shows a comparison between measured and calculated brine temperatures. As can be seen, the peaks depicted in the model temperatures correspond to daytime hours while the troughs correspond to night hours. During the day, evaporation increases as a result of the combination between wind and solar radiation to promote this effect. The variation in maxima and minima is explained by varying weather conditions. In comparison to the measured brine temperatures, the maximum brine temperature predicted by the model was $306.9 \mathrm{~K}$ compared to $307.4 \mathrm{~K}$ while the minimum temperature predicted was $294 \mathrm{~K}$ compared to $300.97 \mathrm{~K}$ respectively. The difference between the average measured brine temperature and simulated brine temperature for the entire test period was $3.3 \mathrm{~K}$. The brine temperature fell considerably during the night because the pan depth was small implying that sufficient energy was not stored in the brine. It can also be observed that the model temperatures are lower than the measured temperatures, but they follow a similar pattern which ascertains that the model fairly predicts the brine temperature. The exception of the two troughs is as a result of the model iteration at these points not solving within the set tolerance. However, the differences between measured and predicted brine temperatures could probably be due to the assumption of one dimensional time dependent steady state heat flow in the pan. Another 
reason for the discrepancy could also be due to the difference between the theoretical value of solar radiation in the brine and that which can be observed experimentally.

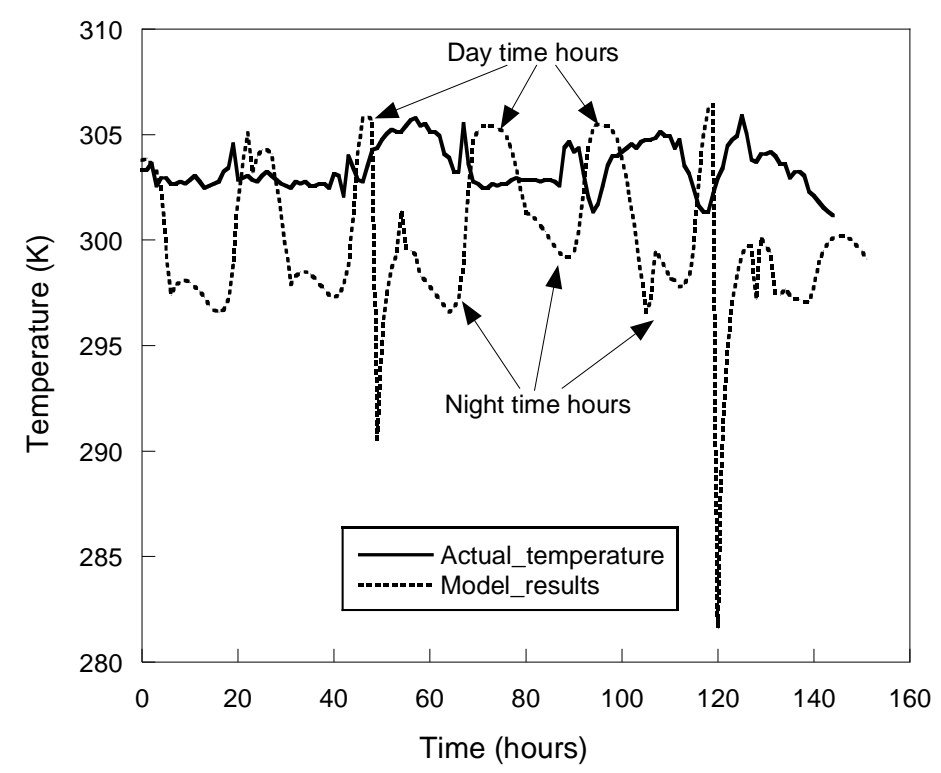

Figure 5. Comparisons between measured and model brine temperatures

\subsubsection{Effect of evaporation}

The heat transfer due to evaporation compared with reported solar insolation is shown in Figure 6.

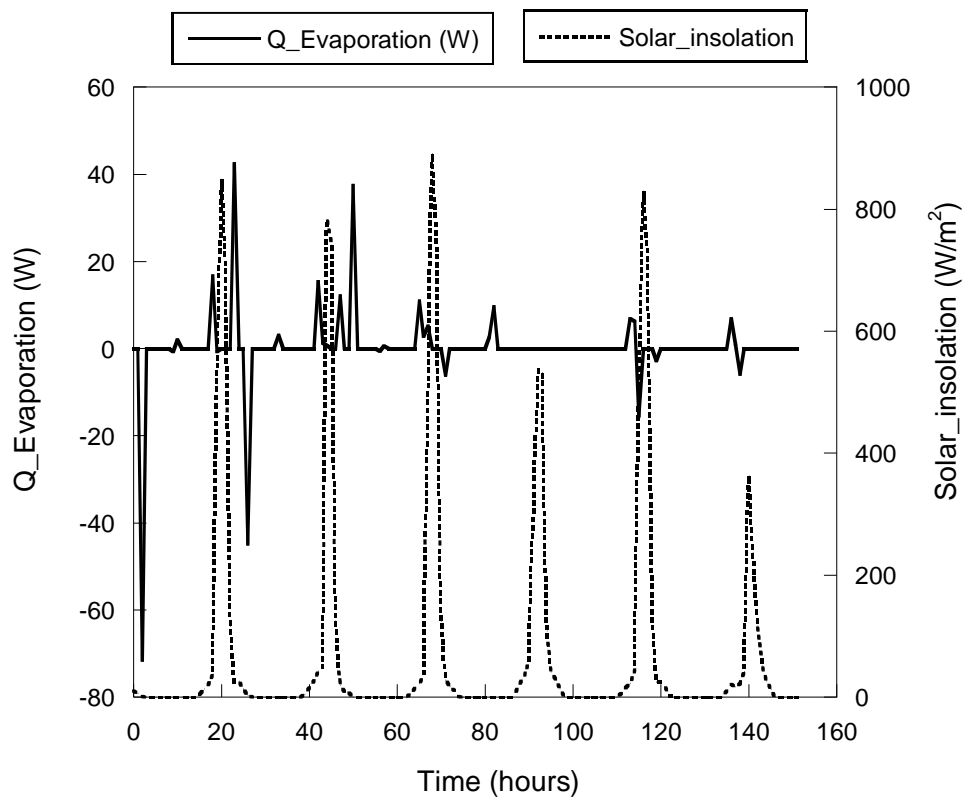

Figure 6. Heat loss due to evaporation variation with time

It is observed that most of the evaporation takes place during day with high insolation levels. During day, most of the incident solar insolation received by the pan is used for evaporation and little energy is stored. Furthermore, the thin layer of the brine depth implies a small thermal capacitance and storage thermal storage capacity which leads to a shorter response time to solar insolation (Zhang et al., 1993). The thin 
brine layer is heated up immediately and the absorbed radiation is used to evaporate the brine immediately. Negative evaporation is observed during the night owing to low ambient temperature and high relative humidity levels hence condensation of water on to the surface of the brine layer. This is explained by the possibility of the vapour pressure of the water being less than the partial pressure of the water in the air which stops evaporation or the reversal of the flow of vapour. Moreover, it should be noted that because of the heat storage in the pan, some evaporation occurred overnight.

\subsubsection{Effect of convection}

Figure 7 shows the convection heat rate as a function of time. Results show that heat loss due to convection is dependent on the variation in the onsite wind regimes. It should be noted that during the experimental period, the wind regimes at Lake Katwe were intermittent ranging from $0 \mathrm{~m} \mathrm{~s}^{-1}$ to peak speeds of up to $10 \mathrm{~m} \mathrm{~s}^{-1}$ with surges at times. The convective heat losses increased sharply with increasing wind speeds observed most especially during daytime. To explain this, some parts of the ground are heated up more than others or are shadowed by clouds during the daytime. This effect leads to a temperature gap which causes movement of air masses expressed as wind. During night hours, the temperature gaps are not wide implying that the displacement of air is not noticeable, hence the low convective losses. However, there is convection heat loss during the night where ambient temperatures are lower than during daytime. At night, most of the energy stored by the brine is most likely to be lost by convection and radiation rather than evaporation.

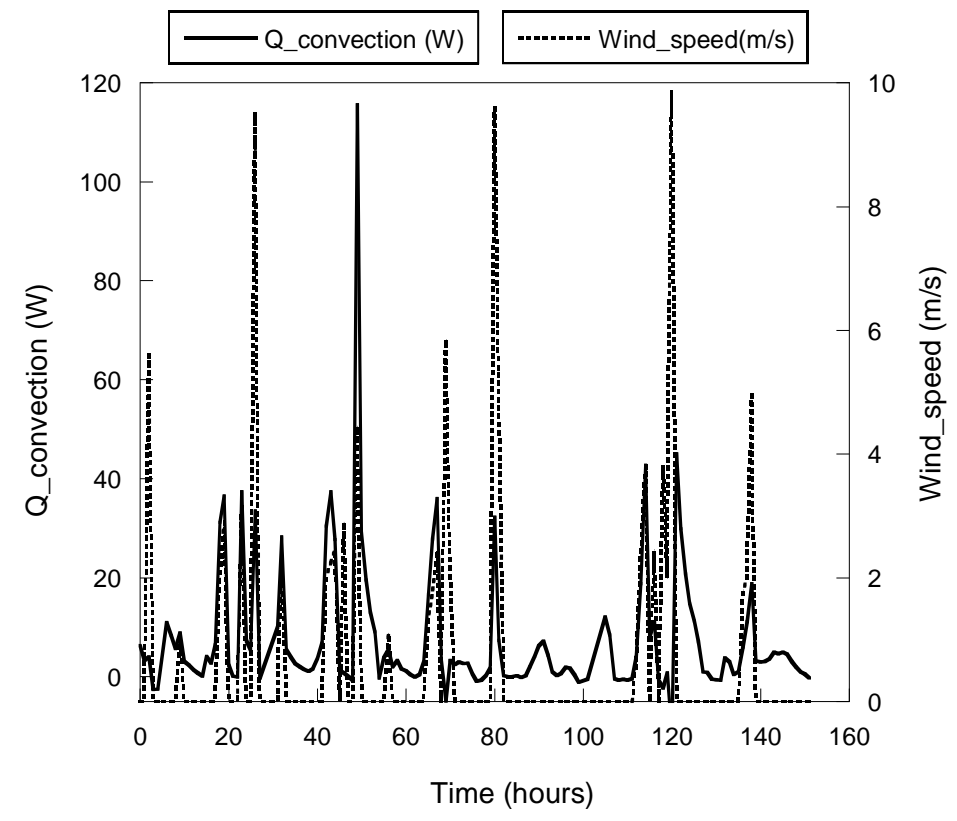

Figure 7. Heat loss due to convection and the observed wind speeds

\subsubsection{Effect of heat flow rate from the ground (pan base)}

Figure 8 shows the variation of heat gain from the ground with time. The average soil temperature at this locality was higher than the brine temperature which resulted in a net heat gain in the pan. When the ambient temperature varies, the soil (heat sink) temperature does not vary significantly. 


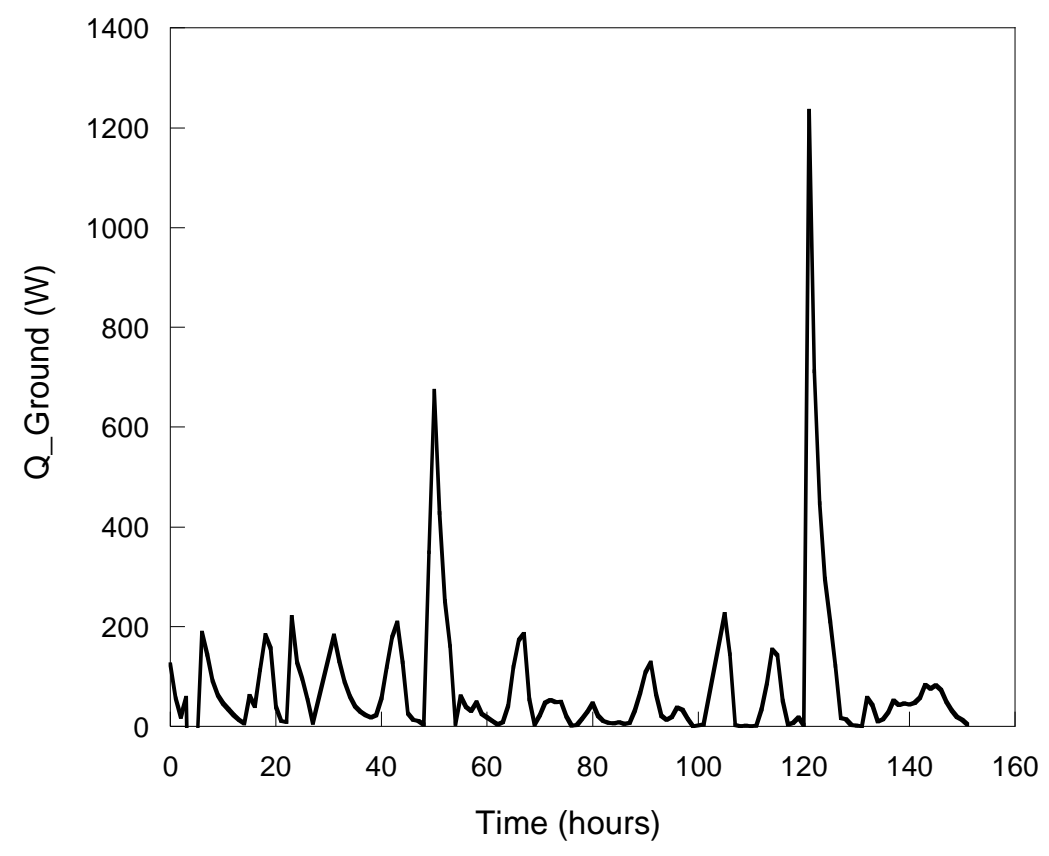

Figure 8. Variation of heat gain from the ground with time

\subsubsection{Radiation effects}

Figure 9 shows the thermal heat variation with time. The pan surface radiated heat to the surroundings because the sky temperature was always higher than the brine temperature. This was more pronounced at night when the brine temperatures were significantly higher than the sky temperature. In this locality which is semi-arid, the skies are open during the night leading to a drop in the sky temperature in the night and an increment during day.

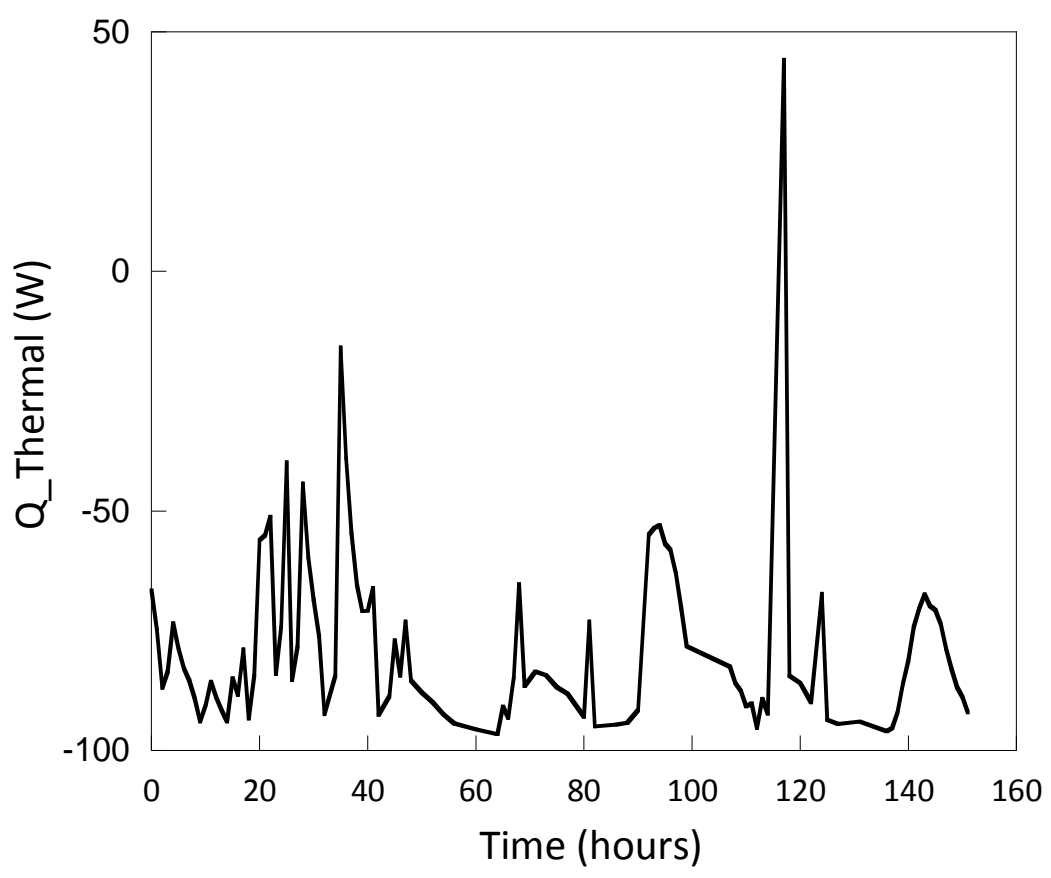

Figure 9. Thermal heat variation with time 


\subsubsection{Solar energy gain variation with time}

Figure 10 shows the solar energy gain variation with time. The solar radiation incident on the brine surface was highest during daytime between 1200 and 1500 hours when the sunshine is most intensive, the ambient temperature highest and the relative humidity lowest corresponding to the peaks. The low values close to zero correspond to night hours with low ambient temperature and insolation.

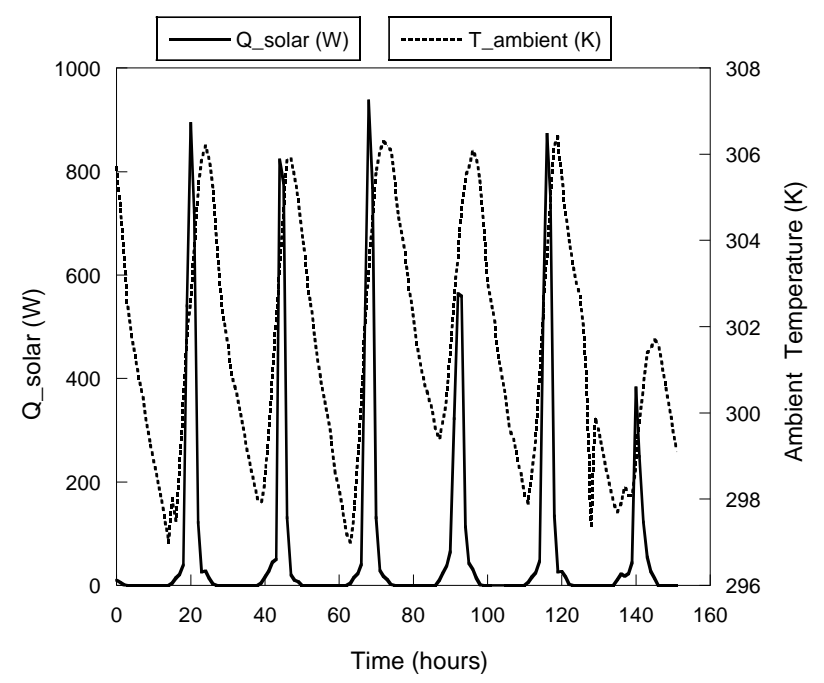

Figure 10. Solar energy gain variation with time

\section{Proposed system and working principle}

Generally, according to the model description and experimental results, in sections 2 and 3 above of this paper, brine evaporation is enhanced essentially by the difference in the humidity ratio of the ambient air and the saturated air at the brine surface. This implies that an increase in the evaporation rate can be achieved by:

- Heating the brine which promotes a decrease in the latent heat of vaporization hence increasing the saturated vapour pressure at the brine temperature;

- Increment in the convection coefficient, by increasing the air flow velocities over the air/brine contact layer;

- Reduction of the relative humidity implying a proportional increase of the saturated vapour pressure through the heating of air.

In order to promote a more efficient concentration of the brine in the salt pans as compared with the present conventional production method at Lake Katwe, the present work proposes the implementation of parabolic trough solar collectors. These collectors are light structures that can achieve high temperatures with high efficiencies at low costs (Kalogirou, 1998). The proposed system consists of a concentrating solar collector, a working fluid storage tank, and a heat exchanger. A schematic representation of the proposed system is shown in Figure 11. In this system, incoming solar radiation is converted into useful heat by the solar concentrator. The working fluid is circulated through the tubes of the collector receiver where it absorbs heat and fed into the storage tank. The hot working fluid from the storage tank is then circulated into the heat exchanger. In the heat exchanger, heat is transferred to the brine pumped from the salt pan. 
The heated brine is later sprayed back over the open area of the salt pan at a higher temperature thereby promoting an enhanced evaporation.

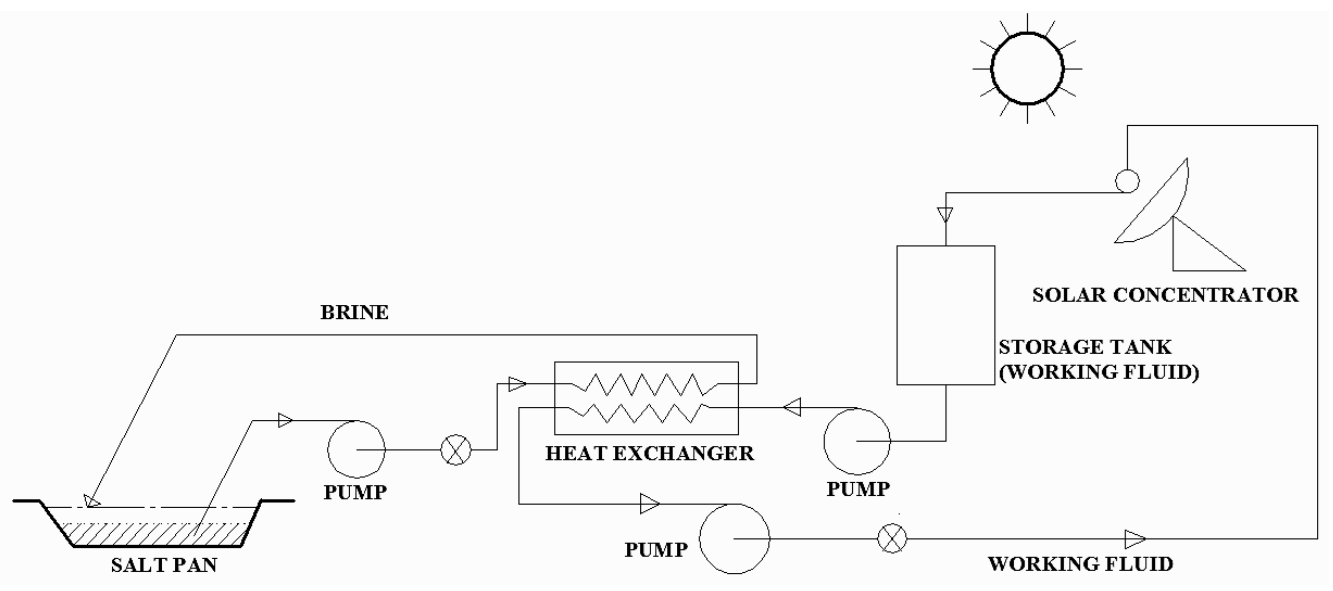

Figure 11. Schematic diagram of the proposed system configuration

\subsection{Analysis}

The heat transfer behavior of the parabolic trough solar collector is based on the following equations (Duffie and Beckman, 2006). The heat gain by the working fluid is expressed as:

$Q=c \cdot 1 \cdot \beta \cdot K$

Assuming a constant heating condition on the tube surface, the outlet temperature of the working fluid after absorbing heat from the collector

$$
\mathrm{T}_{\mathrm{mo}}=\mathrm{T}_{\mathrm{mi}}+\frac{\Pi D L Q}{\mathrm{mc}_{\mathrm{p}}}
$$

The heat exchanger is assumed to be perfectly insulated so that there is no heat loss to the surrounding. Heat transfer occurs only between the working fluid and the brine. The outlet temperatures for fluids are expressed below:

$$
\begin{aligned}
& T_{b o}=T_{b i}+\frac{q}{m_{b} c_{b}} \\
& T_{w o}=T_{w i}+\frac{q}{m_{w} c_{w}}
\end{aligned}
$$

In the present work, the evaporation flux is computed according to the modified version of the Meyer equation (Manganaro and Schwartz, 1985) given as:

$r_{e}=0.00853 C\left(p_{1}-p_{3}\right)\left(1+0.1 V_{3}\right)$

Where:

$\mathrm{p}_{1}=\mathrm{p}_{\mathrm{w}}\left(1-0.7 \mathrm{c}_{1}\right)$

$p_{w}=31.82 \exp \left[\frac{17.42\left(1.8 \mathrm{~T}_{\mathrm{b}}-54\right)}{1.8 \mathrm{~T}_{\mathrm{b}}+492}\right]$ 
The proposed system analyzed comprises of a $4 \mathrm{~m}$ parabolic trough collector with a $1.2 \mathrm{~m}$ wide aperture with a concentration ratio of 156 . The receiver has a reflectivity of 0.7 with a correction factor of 0.8 . Water is used as the working fluid circulating through the parabolic trough collector, and the heat exchanger in $12.7 \mathrm{~mm}$ diameter tubes. The working fluid enters the collector at $30^{\circ} \mathrm{C}$. The specific heat capacity of the water is modeled as $4210 \mathrm{~J} / \mathrm{kgK}$ with a mass flow rate of $0.32 \mathrm{~kg} \mathrm{~s}^{-1}$. The cold fluid entering the heat exchanger is brine from a salt pan at $30^{\circ} \mathrm{C}$ having a specific heat capacity of $3400 \mathrm{~J} / \mathrm{kgK}$ with a mass flow rate of $0.2 \mathrm{~kg} \mathrm{~s}^{-1}$. The evaporation flux is computed taking the constant $C$ of 0.5 for shallow pans. Inputting the data with the reported meteorological data for each day in EES produced the plot shown in Figure 12 which shows the evaporation rate of brine from Lake Katwe during this period.

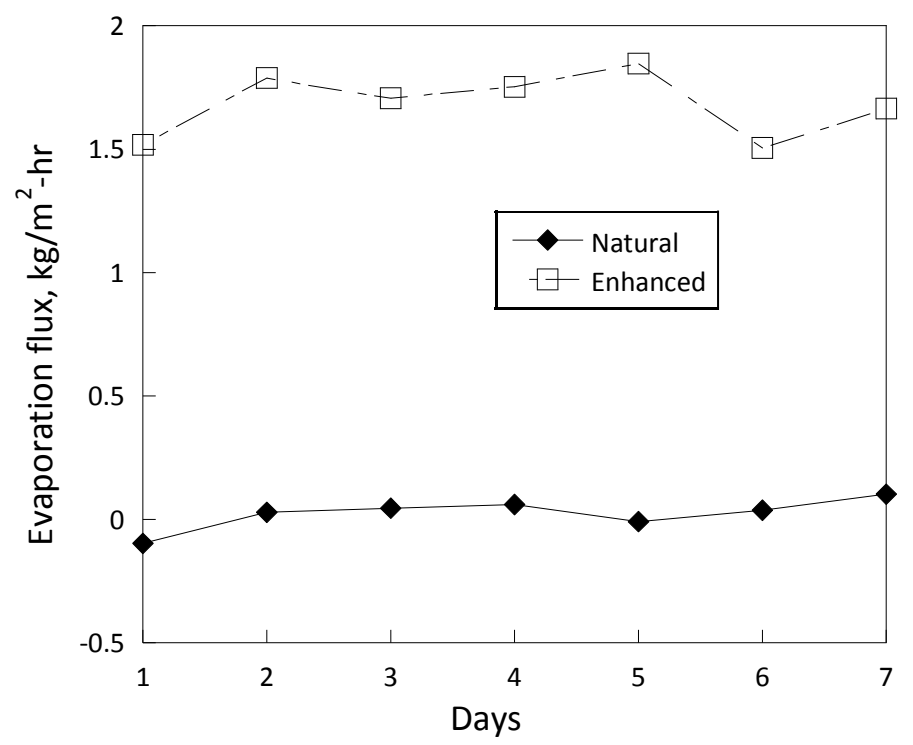

Figure 12. Results showing the evaporation rates of the enhanced model versus the conventional system

A comparison between the evaporation flux resulting from the enhanced system and the present traditional methods over time is done. The average evaporation flux from the traditional system is about $0.02 \mathrm{~kg} / \mathrm{m}^{2}-\mathrm{hr}$ while that of the enhanced system is about $1.68 \mathrm{~kg} / \mathrm{m}^{2}-\mathrm{hr}$, corresponding to a brine temperature increment from $30{ }^{\circ} \mathrm{C}$ to $50{ }^{\circ} \mathrm{C}$. The results show that the evaporation of the brine is increased with the implementation of parabolic solar concentrator as compared to the natural process. The increment in the evaporation flux implies a decrease in the number of days for the crystallization process thus improved productivity. Moreover, the added heat would provide evaporation even during periods where simple solar radiation does not suffice.

\section{Conclusions and future developments}

The following conclusions can be made regarding the solar evaporation of brine for salt extraction at Lake Katwe:

1. The brine density affects its evaporation rate in a predictable manner most especially in the dry seasons. In addition, condensation occurs on heavier brines during the rainy season and during the night with low ambient temperature and high humidity. The high humidity and low ambient temperature create an inverted vapour pressure gradient.

2. A thin salt crust on the brine surface may retard evaporation from heavy brines. Moreover, wave action in the pans helps to prevent such crusts from forming. 
3. The developed model accounted for the effect of the different heat transfer mechanisms involved in the evaporation of brine in salt pans. It showed that evaporation rates increase with increasing brine temperatures while negative evaporation or condensation occurs due to low relative humidity. At high brine temperature than the ambient temperature, sky temperature and soil temperature, the heat due to convection, radiation and ground is lost to the surrounding and vice versa.

4. The implementation of the parabolic trough solar collector technology coupled with heat exchangers has the potential to increase the salt production from the salt pans at Lake Katwe through reduction in the salt crystallization days. Moreover, the proposed system offers added advantages in the fact that it is simple, environmentally friendly, and competitive with other salt extraction techniques. The construction of the system is feasible and does not require significant maintenance costs.

The potential for optimizing the use of solar energy in the improvement of the salt quality and productivity at Lake Katwe exists and as a result, the work reported in the present study will have the following developments:

1. Further investigations of evaporation rates from natural brines of different densities to be estimated by monitoring a single freshwater control evaporation pan placed onsite at Lake Katwe.

2. Detailed economic research to consider pay back analysis and return on investments following implementation of parabolic trough collector technology.

3. The proposed design will be built and tested thereby allowing further refinements in the model. Issues to be considered are material selection for heat exchanger and a study of the behavior of working fluid. Moreover, ground insulation to prevent brine loss by permeation would be investigated.

\section{Acknowledgements}

This study was funded in part by the Government of Sweden through the Swedish International Development Cooperation Agency (Sida) in conjunction with Makerere University. We also acknowledge gratefully the careful review comments from the anonymous reviewers.

\section{Nomenclature}

$\begin{array}{ll}A_{p a n} & \text { Area of the evaporation pan }\left(\mathrm{m}^{2}\right) \\ a & \text { Ambient } \\ c & \text { Concentration ratio } \\ c_{1} & \text { Salt concentration in solution bulk } \\ c_{p} & \text { Air specific heat capacity of the pan film temperature }\left(\mathrm{Jkg}^{-1} \mathrm{~K}^{-1}\right) \\ c_{b, w} & \text { Specific heat capacity of brine and water }\left(\mathrm{Jkg}^{-1} \mathrm{~K}^{-1}\right) \\ D_{A B} & \text { Binary coefficient evaluated at the pan temperature }(-) \\ D & \text { Tube diameter }(\mathrm{mm}) \\ \frac{d T}{d t} & \text { Rate of change of the pan temperature with time. } \\ H & \text { Latent heat of vaporization of the brine in the pan }\left(\mathrm{kJ} \mathrm{kg}^{-1}\right) \\ H_{f g} & \text { Heat transfer coefficient at the grund surface }\left(\mathrm{Wm}^{-2} \mathrm{~K}^{-1}\right) \\ h_{c} & \text { Convective heat transfer coefficient }\left(\mathrm{Wm} \mathrm{K}^{-1}\right)\end{array}$




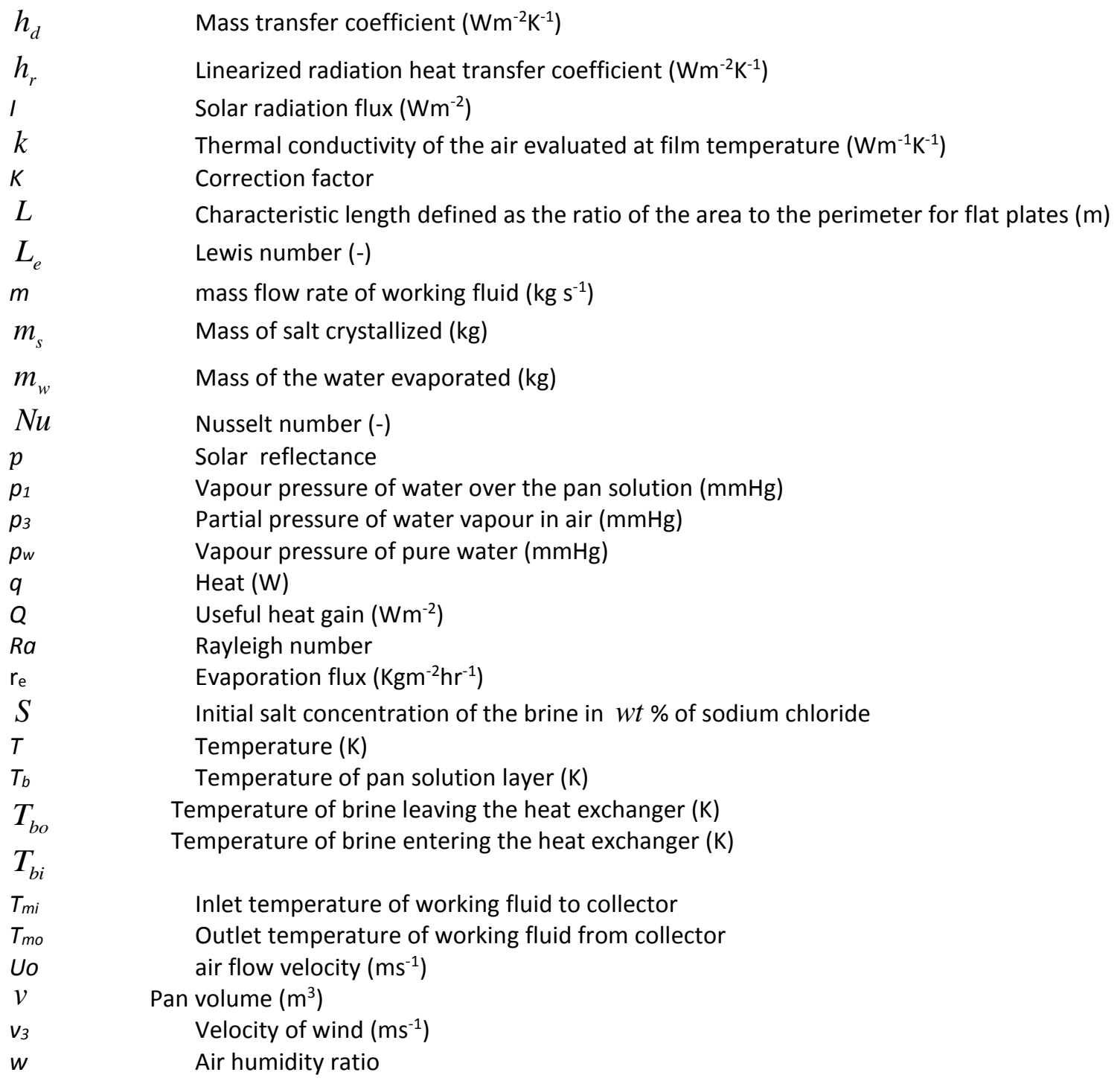

\section{Symbols}

B

$\rho$

$\sigma$

$\varepsilon$

$\alpha$

\section{Subscripts}

air

convection

evaporation

groundwater

in

out

pan

sky

solar
Reflectivity

Brine density in the evaporation pan $\left(\mathrm{kg} \mathrm{m}^{-3}\right)$

Stefan-Boltzmann constant $\left(5.67 * 10^{-8} \mathrm{Wm}^{-2} \mathrm{~K}^{-4}\right)$

Emissivity coefficient of the brine in the pan (-)

Thermal diffusivity of the air $\left(\mathrm{m}^{2} \mathrm{~s}^{-1}\right)$

Air

Convective heat transfer at the pan surface

Evaporation at the pan surface

Ground water inflow or outflow

inflow

outflow

Evaporation pan

Sky

Solar radiant heat gain 
surf Surface

thermal Thermal radiant heat transfer at the pan surface

\section{References}

Abdel H.K. and Al-Naafa M.A. (1993), Enhanced evaporation of saline water in multi-purpose solar desalination units, Desalination, 93, 557-562.

Akridge D.G. (2008), Methods for calculating brine evaporation rates during salt production, Journal of Archaeological Science, 35, 1453-1462

Alvarado F.L. and Klein S.A. (2012), EES-Engineering equation solver, F-chart software.

Chiasson A.D., Rees S.J., Spitler J.D. and Smith M.D. (2000), A Model for Simulating the Performance of a Shallow Pond as a Supplemental Heat Rejecter with closed-Loop Ground Source Heat Pump Systems. ASHRAE Transactions, 106(2), 107-121.

Diaz R.B.F., Stewart S.W. and Brownson J.R.S. (2012), Use of concentrated solar thermal energy systems to enhance sea salt production in southern Spain. World Renewable Energy Forum. Denver, Colorado. May 13-17, 2012.

Duffie J.A. and Beckman W.A. (2006), Solar Engineering of Thermal Processes. $3^{\text {rd }}$ Edition Hoboken: Wiley.

Folchiotto S. (1991), Seawater as salt and water source for solar ponds, Solar Energy, 46, 343-351.

Guijt C.M., Racz I.G, Van Heuven J.M, Reith T and de Haan A.B. (1999), Modeling of a transmembrane evaporation module for desalination of seawater, Desalination, 126, 119-125.

Huang H., Shi M. and Ge X. (1999), The effect of a black insulation sheet on the evaporation rate from a shallow salt pond, International Journal of Energy Research, 23, 31-39.

Horri B.A., Chong M.N., Chen X.D. and Wang H. (2014), Modeling of Solar Evaporation assisted by Floating Light Absorbing Porous Materials, Current Environmental Engineering, 1, 73-81.

Kasedde H., Kirabira J.B., Bäbler M.U., Tilliander A. and Jonsson S. (2014), Characterization of brines and evaporites of Lake Katwe, Uganda, Journal of African Earth Sciences, 91, 55-65.

Kalogirou S. (1998), Use of parabolic trough solar energy collectors for sea-water desalination, Applied Energy, 60, 65-88.

Kirabira J.B., Kasedde H. and Semukuuttu D. (2013), Towards the improvement of salt extraction at Lake Katwe, International Journal of Scientific and Technology Research, 2, 76-81.

Lesino G., Savaria L and Galli D. (1991), Industrial Production of Sodium Sulfate using solar ponds, Solar Energy, 45, 215219.

Manganaro J.L. and Schwartz J.C. (1985), Simulation of an evaporative salt pond, Ind. Eng. Chem. Process Des. Dev., 24, 1245-1251.

Pereira M.C., Mendes J.F., Horta P. and Korovessis N. (2007), Final design of an advanced solar dryer for salt recovery from brine effluent of an MED desalination plant, Desalination, 211(1-3), 222-231.

Tamimi A. and Rawajfeh K. (2007), Lumped modeling of solar-evaporative ponds from the water of the Dead Sea, Desalination, 216, 356-366.

Turk L.J. (1970), Evaporation of brine: A field Study on the Bonneville Salt Flats, Utah 6: 1209-1215

UD, (1997), Feasibility study of the rehabilitation of Lake Katwe Salt Project. Uganda Development Cooperation, Republic of Uganda.

Zeng Y. Yao J. and Horri B.A. (2011), Solar evaporation enhancement using floating light-absorbing magnetic particles. Energy and Environmental Science, 4, 4074-4078.

Zhang Y.Z., Ge X.S. and Li Y.F. (1993), Mathematical Simulation of Evaporating Brine by Solar Radiation for the production of Salt, Journal of Thermal Science, 2(2), 207. 